\title{
Student Success for All: Support for Low-Income Students at an Urban Public University
}

Mark Potter

\begin{abstract}
Although federal financial aid has increased in recent years, the costs of college tuition and living expenses have increased even more, leaving larger numbers of students with unmet need. Restructuring of financial aid, however, is insufficient to address the problem of diverging attainment gaps between low-income students and their more advantaged peers. Low-income students share patterns and traits that put them at greater risk of dropping out of college. In response, the Lumina Foundation published the report Beyond Financial Aid, which identifies six strategies for supporting low-income students, offers examples of how those strategies may be implemented, and provides an institutional self-assessment tool. At Metropolitan State University of Denver, a cross-functional team of faculty and staff at MSU Denver gained considerable insight by using and discussing the Beyond Financial Aid assessment tool. The action plan that emerged from the team's work consists of five goals: (a) Take advantage of easy wins; (b) use data to know our low-income students; (c) increase broad-based support for lowincome students; and (d) foster culture change; and enhance financial literacy. Additionally, MSU Denver has leveraged partnerships to strengthen support for its low-income students as a natural extension of the University's regional stewardship mission.
\end{abstract}

\section{Keywords}

Equity; attainment; partnerships

\section{Introduction}

For metropolitan colleges and universities, meeting degree completion goals and closing the achievement gap increasingly means providing targeted support for low-income students. Although federal financial aid has increased in recent years, the costs of college tuition and living expenses have increased even more, leaving larger numbers of students with unmet need. Low-income students have seen their share of unmet need increase the fastest, while more aid has gone to more economically advantaged students in the middle and upper classes (Engle \& Tinto, 2008; Lynch, Engle, \& Cruz, 2011). Because low-income students, who are often also first-generation students, have fewer family resources to draw from and have greater unmet financial need in covering their costs of education, they are more at risk of dropping or stopping out before reaching their educational goals (Chaplot, Cooper, Johnstone, \& Karndjeff, 2015). "Student success" equates to students meeting their educational goals, which typically means obtaining a degree or certificate and gaining knowledge and skills for career-readiness or postgraduate studies. Student success initiatives at colleges and universities aim to support students through graduation, so that they leave with a credential and are ready to pursue their postgraduate plans. As access to higher education has expanded, more and more students are leaving college before graduating; an estimated 37 million adults nationwide have some college credit

Metropolitan Universities Vol. 28 No. 2 (Spring 2017), DOI: 10.18060/21512 
but no degree. Many of these individuals, furthermore, carry student loan debt that creates additional economic hardship beyond what they began with as they entered college ("Some College, No Degree | American RadioWorks," 2011). Student success, thus, is critical to the postsecondary credential attainment that can lift low-income individuals into a more secure and prosperous life.

The financial challenges that low-income students face in obtaining a college credential present a fundamental equity issue for higher education and for society at large. College attainment rates in the U.S. have only increased from $7 \%$ to $9 \%$ among adults in the lower income quartile since the 1970s. (Cahalan \& Perna, 2015). Furthermore, low-income students who enter college with above-average aptitude test scores have a lower graduation rate than more affluent students with lower test scores (New York Times, 2012). Because college degrees are so closely tied to earnings potential, the barriers to student success for low-income students perpetuate society's worsening inequality ("Earnings and unemployment rates by educational attainment," n.d.).

Restructuring federal, state, and institutional practices, to place a greater emphasis on need-based scholarships and aid, is part of the solution to increasing opportunity for low-income students. Unfortunately, trends have run counter to that ideal, as, for example, "state grants not based on need have grown at triple the rate of need-based grants over the past 10 years" (Lynch, Engle, \& Cruz, 2011). More than changes to financial-aid practices is needed, though, to create equitable outcomes. Low-income students, like first-generation students, share patterns and traits that put them at greater risk of dropping out of college. Demographically, these students, on average, are more likely to be older, have a disability, come from a minority background, have dependent children or be single parents, and be financially independent of their parents. Low-income students are also more likely than their more affluent peers to delay entry into college following high school, live off campus, attend part-time, and work more in paid positions off campus. Although these traits or patterns are very much interrelated, each of them separately have been shown to be associated with lower levels of college completion (Engle \& Tinto, 2008). For lowincome students who enter college without the support structures that their more affluent peers have, a seemingly minor life event, such as a broken-down car or a stolen laptop could be enough to derail their educational progress and cause them to drop out.

Understanding the challenges that low-income students face, in 2015 the Lumina Foundation published the report Beyond Financial Aid, which identifies six strategies for supporting lowincome students, offers examples from two- and four-year institutions of how those strategies may be implemented, and provides an institutional self-assessment tool (Chaplot, Cooper, Johnstone, \& Karndjeff, 2015). The report notes that more and more low-income students are attending college; identifying and offering support to those students are integral to achieving equity in educational outcomes.

Metropolitan State University of Denver, a large, public comprehensive university in downtown Denver, CO, proudly serves a student body that is reflective of the students who are the focus of Beyond Financial Aid. With modified open-admissions and a reputation for being the least expensive four-year institution in Colorado, MSU Denver's student body of 20,000 undergraduates is roughly one-third eligible for Pell, one-third first generation, and close to $40 \%$ minority. In Colorado, the Master Plan for Higher Education calls for increasing the number of college credentials awarded statewide by 1000 each year until workforce needs are met, with the goal of $66 \%$ of adults holding postsecondary credentials by 2025 . Colorado has the second 
largest attainment gap across racial/ethnic groups in the nation, however, and the Master Plan for Higher Education acknowledges that the state's college-completion goals will only be met by closing the attainment gap (Colorado Commission on Higher Education, 2012). With higher numbers of undergraduate students from underserved backgrounds than any other four-year institution in the state, MSU Denver has an outsized role to play in meeting the state's completion goals. Improving retention and graduation rates is thus a priority for the University, and addressing students' financial hardship has been part of that work since an internal 2015 study found financial issues as one of the major reasons why students stop or drop out.

A cross-functional team at MSU Denver gained considerable insight by using and discussing the Beyond Financial Aid assessment tool. Each member of the team, comprised of the Associate Vice President for Undergraduate Studies, the chair of the Department of Human Services, and staff members from Student Engagement and Wellness, Financial Aid, Student Academic Success, and Women's Studies and Services, completed the assessment individually. Then, over the course of three separate meetings, team members compared and compiled findings into an action plan. The team discovered that many of the supports described in Beyond Financial Aid were already in place. However, the findings confirmed that more work needed to be done in order to ensure that more students would benefited from these services.

The action plan that emerged from the team's work consists of five goals. These goals align closely with the six strategy recommendations that frame Beyond Financial Aid. At MSU Denver, we are seeking to:

1. Increase support for our low-income students by exploring and taking advantage of shortterm easy wins;

2. Use data to identify and support low-income students;

3. Increase broad-based support for low-income students through efforts that are comprehensive, proactive, and intentional;

4. Foster culture change that empowers students and creates safe spaces for students to ask for help; and

5. Enhance student financial literacy and understanding of the financial implications of their choices.

\section{Strategy 1: Take Advantage of Easy Wins}

Beyond Financial Aid mentions strategies that the MSU Denver team thought could be developed as early and easy wins to bring meaningful support to low-income students. MSU Denver's Accounting Department had for years partnered with local agencies to provide tax preparation assistance, under the Voluntary Income Tax Assistance (VITA) program, at community centers throughout Denver. Each year accounting students gain hands-on experience applying tax law to the preparation of tax returns while providing a service to the community. The easy win that came in response to the Beyond Financial Aid institutional self-assessment was to establish an on-campus site, centrally located and easily accessible to MSU Denver students, where eligible students could obtain free tax return assistance. Approximately 100 individuals, mostly MSU Denver students, were assisted at this site during the 2015 tax season at a total benefit to them of $\$ 53,000$. Several students reported that as a result of this service they obtained refunds after thinking that they would owe money in taxes. This first year was so successful, both from a learning standpoint in the Accounting Department and from a student 
services standpoint, that plans are underway to double the on-campus service for the 2016 tax season.

\section{Strategy 2: Use Data to Know Our Low-Income Students}

Unmet need has often been cited as a major determining factor that affects a student's likelihood of persisting (Chaplot, Cooper, Johnstone, \& Karndjeff, 2015; Lynch, Engle, \& Cruz, 2011; "Case Study," 2015). At MSU Denver, despite offering the lowest in-state tuition of any fouryear institution in Colorado, $56 \%$ of the student body carries unmet need according to data pulled from student financial records from 2010 to 2014. An internal analysis conducted on these data did not demonstrate that a simple correlation exists between unmet need and risk of stopping or dropping out. On the other hand, a subset of students with unmet need - those between $\$ 1,000$ to $\$ 2,000$ of unmet need per year — did, according to the same historical data, dropout in greater numbers than either students with less unmet need or greater unmet need (Talich, 2016). These findings suggest that a more complex interplay is at work between unmet need, a student's socioeconomic status, students' willingness to take loans to complete their degrees, and possibly other behaviors and traits that are associated with low-income students. Further analysis shows that students from the lowest socio-economic status, those with an Estimated Family Contribution (EFC) of $\$ 0$ to $\$ 649$, and with unmet need in the same range of $\$ 1000$ to $\$ 1999$, have the highest likelihood of not persisting.

MSU Denver students appear to reflect the first-generation, low-income, students identified in Engle and Tinto (2008) who are more likely to be minorities, begin college later in life, attend college part-time, and work full-time. We know, for example, that African American students at MSU Denver are the most likely (75\%) to have unmet need, followed by Latino students $(65 \%)$ and then White students (50\%). African Americans and Latinos are also most likely to be Pelleligible, attend part-time, and take longer to graduate (Metropolitan State University of Denver, 2016). Ongoing inquiry that disaggregates the unmet-need data by various groupings such as race, ethnicity, first-generation or age will enable the Beyond Financial Aid team to refine its understanding of who our low-income students are, what the challenges are that they face, and how successful we are in making support services available to them.

\section{Strategy 3: Increase Broad-Based Support}

MSU Denver has long recognized the mission-driven imperative to support a diverse student body that includes low-income students. Since 2009 for example, the University has had a food pantry in partnership with the Food Bank of the Rockies to provide food, in a confidential setting, to students in need. Additionally, a team of staff and faculty worked over the course of several months to identify housing options and resources for students who were homeless or at risk of becoming homeless, and the Institute of Women's Studies and Services provides referrals to students in need of housing, transportation assistance, low-cost child care, and public benefits.

On the other hand, whereas this patchwork of supports and services exists for low-income students at MSU Denver, the Beyond Financial Aid team that conducted the institutional selfassessment found that knowledge and use of the support services were minimal. In response, the Beyond Financial Aid team has been working to create a map of resources for students, along 
with information sheets for faculty and staff, in order to refer students effectively to support services. Additionally, the Beyond Financial Aid team has shifted focus in part from assessment and planning to rapid response. As such, the team works to ensure that the right kind of support is provided to meet shifting needs. As this team is evolving, the model of an "economic distress task force" described by Munin and Enos (2016) is providing a blueprint to help guide this work.

\section{Strategy 4: Foster Culture Change}

Attention to culture is critical for ensuring that more low-income students receive support. MSU Denver's Beyond Financial Aid team is working to remove the stigma and create a climate in which students feel safe asking for help in financial matters. The team has expressed awareness of the need to publicize support for low-income students without using labels that could cause students to turn away. In order to normalize accessing support, the team is developing a resource guide for faculty and staff to be able to refer students who, on their own, may not find their way to services. Additionally, MSU Denver is developing a social benefits screening service for students modeled on similar programs described in Beyond Financial Aid (Chaplot, Cooper, Johnstone, \& Karndjeff, 2015). Effective Spring 2017, a Master's in Social Work student intern position has been filled on campus to develop and maintain a comprehensive list of social benefit programs and community resources, meet students for intake to identify needs, and prescreen students for public benefits. Although receiving public benefits is an intensely personal choice, we want to raise awareness of options and help students overcome barriers, if doing so means not leaving resources on the table that might contribute to a student's success.

\section{Strategy 5: Enhance financial literacy}

College students face having to make multiple financial decisions each year that could potentially have serious long-term financial implications. The trade-offs of their choices are not always immediately apparent to them. For instance, a student may choose to work more in order to avoid student debt. However, they may in the process take fewer credit hours, and push graduation out further. Moreover, they mayincrease the total cost of a degree while stretching out the length of time during which an adverse life event might prevent completion. These trade-offs weigh even more heavily on low-income students. In addition, if they are also first-generation students they may not have the experience or insight of family members to help them make those decisions.

For all these reasons, financial literacy is a priority at MSU Denver. One message that has been at the center of these efforts is the "15-to-finish" message. Students at MSU Denver are able to enroll in 13 to 18 credit hours for the same price as 12 credit hours. With data to show that our students who take 15 credit hours perform just as well, if not better than students who take 12 credit hours, we began a texting, email, and orientation communications campaign in Summer 2016 to encourage students to think of 15 credit hours as the norm for full-time students ("DATA | 15 to Finish," n.d.; "Study Finds First-Year Students Who Take 15 Credits Succeed | Inside Higher Ed," 2016.). The outcome from this initial concerted effort was that $44 \%$ of the incoming first-time to college students enrolled in 15 credit hours. 
Additionally, the Office of Financial Aid is taking proactive steps to ensure that students understand responsible student loan borrowing. MSU Denver has partnered with SALT, a nonprofit organization that specializes in financial literacy and default management. Students are encouraged to complete various financial literacy modules, and the Office of Financial Aid is exploring ways to incorporate these modules into various financial aid processes. Additionally, programs like First Year Success incorporate SALT into financial literacy workshops. Lastly, students now have up-to-date, on-demand access to their accrued subsidized and unsubsidized loan amounts and what they can anticipate as their estimated monthly repayment at their current borrowing levels.

\section{The Value of Partnerships}

Chaplot, Cooper, Johnstone, \& Karndjeff (2015) recommend leveraging partnerships to maximize support for low-income students. Community partners can be key to filling gaps in services and programs. Community engagement is a priority at MSU Denver, as articulated in the University's strategic plan. Leveraging partnerships for the benefit of low-income students thus resonates as a natural extension of the University's regional stewardship mission. Examples of such partnerships include: (a) the work that MSU Denver does with the Denver Asset Building Coalition to make possible the VITA program that provides students with tax return assistance; and (b) the partnership with the Food Bank of the Rockies, of which the MSU Denver Food Bank is an affiliated agency.

The possibilities for innovative partnerships extend beyond the examples provided in Beyond Financial Aid. For example, MSU Denver completed a successful summer-bridge pilot in 2016 in partnership with the Denver Housing Authority (DHA). The DHA provided Federal workforce funding from its Summer Youth Employment Program. MSU Denver established itself as a work site, and identified offices on campus, where scholars, all of whom were Fall admits transitioning from high school, could work. The scholars were paid to spend six weeks on campus prior to the start of Fall semester. Working on campus helped the scholars form meaningful connections to staff, faculty, and peers. The scholars also participated in college readiness workshops as part of their paid work. Each of the 11 students in the pilot matriculated in the Fall even though they all had multiple factors that put them at risk of summer melt. One scholar reported at the end of the program, as she was readying for the start of her first semester as a college student, that participating in the summer bridge pilot was the best decision she had ever made.

Not all partnerships, however, produce the desired results. Under the goal of taking advantage of easy wins, MSU Denver had hoped that a partnership with a neighboring technical college might provide low- or no-cost automobile repair services to our students in need. The Automobile Repair Services curriculum at the technical college, however, cannot accommodate on-demand repairs that fall outside its scaffolded lesson plans. Although that partnership did not yield the service we had hoped it would, the Beyond Financial Aid self-assessment process nonetheless identified car repair as a support service that our low-income students need, and our commitment continues to finding a solution.

\section{Conclusion}


The national imperative to close the achievement gap between low-income students and their more advantaged peers is gaining increasing attention through publications such as Beyond Financial Aid (Chaplot, Cooper, Johnstone, \& Karndjeff, 2015). Much of the unmet need of lowincome students could be addressed by a commitment to restructuring financial aid and scholarships. Unfortunately, at many institutions and in many states, the political will to shift aid and scholarships to need-based is simply not present (Lynch, Engle, \& Cruz, 2011). Even if such changes occurred, however, low-income students would continue to face challenges that have a potential to derail them in ways that do not apply to their peers with more stable financial means. A much broader commitment is thus needed to provide the holistic support services that are necessary. MSU Denver is committed to the success of all of its students, and that commitment extends to low-income students who make up a significant portion of the student body. The process of putting the needed supports in place received a boost from Beyond Financial Aid and will continue apace as long as achievement gaps persist at MSU Denver across income levels. Success in supporting our low-income students will be achieved when we see those achievement gaps disappear; the work, on the other hand, will continue as long as low-income students see education as one of their pathways to improving their conditions.

The author thanks Lori Kester for input into the content and editing of this article.

\section{References}

Cahalan, M., \& Perna, L. (2015). Indicators of higher education equity in the United States: 45 Year Trend Report. The Pell Institute for the Study of Opportunity in Higher Education. Retrieved from http://www.pellinstitute.org/downloads/publicationsIndicators_of_Higher_Education_Equity_in_the_US_45_Year_Trend_Report.pdf

Case study: Georgia State University. (2015, December 8). Retrieved from http://postsecondary.gatesfoundation.org/georgia-state-university-case-study/

Chaplot, P., Cooper, D., Johnstone, R., \& Karndjeff, K. (2015). Beyond financial aid: how colleges can strengthen the financial stability of low-income students and improve student outcomes. Indianapolis, IN: Lumina Foundation. Retrieved from https://www.luminafoundation.org/beyond-financial-aid

Colorado Commission on Higher Education. (2012). Colorado competes: A completion agenda for higher education. Denver, CO.

DATA | 15 to finish. (2015, Fall). Retrieved from http://15tofinish.com/data/

Unemployment rates and earnings by educational attainment. (2017, April 20). Retrieved from http://www.bls.gov/emp/ep_chart_001.htm

Engle, J., \& Tinto, V. (2008). Moving beyond access: College success for low-income, firstgeneration students. The Pell Institute for the Study of Opportunity in Higher Education. 
Retrieved from http://www.pellinstitute.org/publicationsMoving_Beyond_Access_2008.shtml

How one college helps its students navigate the maze of social Sservices. (2016, August 19).

Retrieved from http://www.chronicle.com/article/How-One-College-HelpsIts/237505/?key=O998qdDb93HBMW6pFSQu7ie3xi2v8VvM9PZZxrAebD9AKK9pmGpt1 WRzfcJaWrpdnFVWU16S3ljOG5VN2xZSmFoalZvajg3UlBvLW0tNTc4bkZCbG9RX3NuNA

Lynch, M., Engle, J., \& Cruz, J. L. (2011). Priced out: How the wrong Ffinancial-aid policies hurt low-income students. The Education Trust. Retrieved from http://eric.ed.gov/?id=ED520199

Metropolitan State University of Denver. (2016). Census fall undergraduate student profiles. Denver: Metropolitan State University of Denver.

Munin, A., \& Enos, M. (2016). Food, shelter, and success: Mitigating risk for low-income college students. In V. Pendakur (Ed.), Closing the Opportunity Gap: Identity Conscious Strategies for Retention and Student Success (pp. 126-144). Sterling, Virginia: Stylus.

New York Times. (2012, December 22). Affluent students have an advantage. Retrieved from http://www.nytimes.com/interactive/2012/12/22/education/Affluent-Students-Have-anAdvantage-and-the-Gap-Is-Widening.html?_r=0

Study finds first-year students who take 15 credits succeed | Inside Higher Ed. (2016, June 30). Retrieved from https://www.insidehighered.com/quicktakes/2016/06/30/study-finds-firstyear-students-who-take-15-credits-succeed

Talich, K. (2016). Unmet financial need analysis. Denver, CO: Metropolitan State University of Denver. 


\section{Author Information}

Dr. Mark Potter is Associate Vice President for Undergraduate Studies at Metropolitan State University of Denver. He holds a PhD in History from UCLA and has been a history professor and department chair at the University of Wyoming as well as founding director of the Center for Faculty Development at Metropolitan State University of Denver. He is responsible in his current position for multiple offices that advance student success and foster high impact practices.

Mark Potter

Undergraduate Studies

Metropolitan State University of Denver

Campus Box 48

P.O. Box 173362

Denver, CO 80217-3362

E-mail: mpotte10@msudenver.edu

Telephone: 303-352-7331 